\title{
Endokron restorasyonlar
}

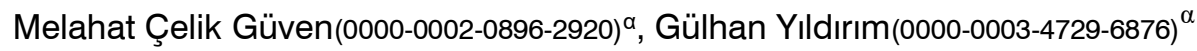

Selcuk Dent J, 2019; 6: 201-205 (Doi: 10.15311/selcukdentj.339075)

Başvuru Tarihi: 20 Eylül 2017 Yayına Kabul Tarihi: 24 Nisan 2018

ÖZ

Endokron restorasyonlar

Endodontik tedavi görmüş ve kron harabiyeti fazla olan dişlerin restorasyonunda uygulanacak tedavi ile ilgili bir fikir birliğine hala varılamamıştır. Geleneksel yöntemde bu dişlerin tedavisi kanal içi postkor üzerine uygulanan tam kron restorasyonları ile yapılmaktadır. Fakat bu tedavi esnasında sağlam dokuların da kaldırılması sebebiyle geriye kalan diş dokusunun biyomekanik özellikleri değişmekte ve güçsüzleşmektedir. Adeziv sistemlerin gelişmesine parelel olarak bu vakalarda yeni tedavi alternatifleri uygulanmaktadır. Endokron restorasyonlar aşıı madde kaybına sahip endodontik tedavi görmüş dişlerin tedavisinde, post-kron restorasyonlara alternatif olarak kullanılan yeni bir tedavi seçeneğidir. Endokron restorasyonlar tek parça olarak üretilmektedir. Bu restorasyonlar pulpa odasından ve kavite duvarlarından destek aldığı için makromekanik tutuculuk sağlarken, adeziv sistem ile simante edilmesi sayesinde mikromekanik tutuculuk da elde edilmektedir. Endokron restorasyon uygulamaları göreceli olarak daha basit ve seans sayıları kısadır. Preparasyonları sırasında sağlam diş dokusunun daha az kaldırılması, kalsifiye, tıkalı ve kökleri eğri olan dişlerde uygulanabilmesi, kökte perforasyon ve kırık oluşturma riskinin bulunmaması ve oklüzal mesafenin az olduğu hastalarda uygulanabilmesi endokron restorasyonların avantajlarındandır. Endokron restorasyonlar ile yapılmış literatürde az sayıda çalışma mevcuttur. Bu derlemenin amacı yakın bir geçmişten itibaren kullanılan endokron restorasyonların tarihçesini, sınıflamasını, avantajlarını ayrıntılı bir biçimde inceleyerek konuyla ilgili yapılan in vivo ve in vitro çalışmaları değerlendirmektedir.

\section{ANAHTAR KELIMELER}

Adeziv restorasyon, aşırı madde kaybı, endodontik tedavili diş, endokron

Endodontik tedavi görmüş ve kron harabiyeti fazla olan dişlerin restorasyonunda uygulanacak tedavi çoğu zaman klinisyenleri düşündürmektedir. ${ }^{1-3}$ Geleneksel olarak bu dişlerin tedavisi kanal içi post-kor üzerine uygulanan tam kron restorasyonları ile yapılmaktadır., ${ }^{2,3}$ Ancak geleneksel tedavi sırasında sağlam dokularında kaldıııması geriye kalan diş dokusunun biyomekanik özelliklerini değiştirmekte ve güçsüzleştirmektedir. Ayrıca post tedavisi uygulanırken kökte perforasyon ve kırık oluşturma riskinin bulunması geleneksel sisteme alternatif yöntemlerin araştırılmasına sebep olmuştur..$^{3-5}$ Adeziv simanların gelişmesine paralel olarak son yıllarda geleneksel tedavi yöntemlerine alternatif olarak endokron restorasyonlar uygulanmaktadır. $^{6}$

Endokron restorasyonlar tek parça olarak üretilmektedir. Kanal içi postlardan farklı olarak pulpa odasından ve kavite

\section{ABSTRACT \\ Endocrown restorations}

Treatment protocol of extensively damaged endodontically treated teeth is still controversial. In the traditional method, the treatment of these teeth is performed with full crown restorations and post-core. However, removal of intact tissue during conventional treatment changes and weakens the biomechanical properties of the remaining dental tissue. New treatment alternatives are applied in parallel to the development of adhesive systems. Endocrown restorations are a new treatment option used as an alternative to postcor supported crown restorations in the treatment of extensively damaged endodontically treated teeth. Endocrown restorations are produced in one piece. Endocrown restorations provide macromechanical retention from the wall of the pulp chamber and the cavity walls while micromechanical retention is achieved by cementation with an adhesive system. Endocrown restorations are relatively easy and require less chairside time and fewer visits. Endocrown restorations have advantages like; simplicity of application, fewer treatment sessions, the less removal of intact dental tissue during preparation and they can be used in teeth with short, calcified, curved canals and with limited occlusal distance. There are few studies about endocrown restorations. The purpose of this review is to investigate the history, classisfication and advantages of endocrowns and evaluate the in vivo and in vitro studies on this subject.

\section{KEYWORDS}

Adhesiv restoration, extensively damaged, endodontic treatment, endocrown

duvarlarından destek alıp adeziv simanlar ile simante edilmektedirler., ${ }^{7,8}$ Literatürde endokron restorasyonlarını ilk uygulamış olan araştırmacı Pissis ${ }^{9}$; endokronları monoblok porselen teknik olarak tanımlamıştır. Endokron restorasyonların tanımı ise ilk olarak 1999 yllında Bindl ve Mörmann ${ }^{10}$ tarafından yapılmıştır. Endokron restorayonlar pulpa odasından ve kavite duvarlarından destek aldığı için makromekanik tutuculuk sağlarken, adeziv sistem ile simante edilmesi sayesinde mikromekanik tutuculuk da elde edilmektedir. ${ }^{11}$

Endokron restorasyonlar ark üzerindeki tüm dişlere uygulanabilmektedir. Literatürde endokron restorasyonların aşırı madde kaybı bulunan kesici dişler ${ }^{12}$, premolar $^{13}$ ve molar

${ }^{\alpha}$ İstanbul Yeni Yüzyıl Üniversitesi, Diş Hekimliği Fakültesi, Protetik Diş Tedavisi Anabilim Dalı, İstanbul 
dişlere uygulandığı çalışmalar mevcuttur. ${ }^{13,14}$ Ancak yoğun olarak molar dişlere uygulanmaktadır. Bu durumun; molar dişlerin genişliklerinin daha fazla olması sayesinde tutuculuğun elde edildiği yüzey alanının artması ve premolar dişlere kıyasla horizontal kuvvetlere daha az maruz kalması sayesinde kırıma dirençlerinin yüksek olması ile açıklanabilmektedir. ${ }^{6,13}$ Endokron restorasyonların sonlu elemanlar analizi ile incelendiği bir çalışmada endokron restorasyonların post kron restorayonlara göre daha düşük stres değerleri oluşturduğu rapor edilmiştir. ${ }^{15}$ Endokron restorasyonlar tek parça olacak şekilde üretildiği için adezyon sadece diş ve restorasyon arasında gerçekleşir. Bu nedenle adeziv başarısızlığın minimalize edildiği belirtilmektedir. ${ }^{12}$ Endokron restorasyonların kırıma dayanımlarının geleneksel yöntemler ile karşılaş̧ıııldığında daha yüksek olduğu bildirilmektedir. ${ }^{16}$

\section{Endokron retorasyonların avantajları}

- Preparasyon sırasında sağlam dokuların daha az kaldırılması

- Daha ekonomik olması

- Seans sayılarının az olması

- Tedavinin daha basit olması

- Kısa kanallı dişlerde uygulanabilmesi

- Köklerin eğri olduğu dişlerde uygulanabilmesi

- Kalsifiye kanalların olduğu olgularda uygulanabilmesi

- Interoklüzal mesafenin yetersiz olduğu olgularda uygulanabilmesi

- Supragingival restorasyonlar hazırlandığı için plak tutulumunun daha az olması olarak sıralanabilmektedir. ${ }^{12,17-19}$

\section{Endokron restorasyonların sınıflandırılması}

Endokron restorasyonların sınıflaması preparasyon sonrası kalan diş dokusu miktarını esas alarak yapılmaktadır ve üçe ayrılmaktadır.

1. En az iki sağlam duvarın olduğu diş preparasyonunu tanımlamaktadır.

2. Maksimum bir duvarın orijinal yüksekliğinin yarısından daha fazla bir yüksekliğe sahip olduğu diş preparasyonunu tanımlamaktadır.

3. Tüm duvarların orijinal yüksekliğinin yarısından daha düşük olduğu diş preparasyonunu tanımlamaktadır (Şekil 1). ${ }^{20}$

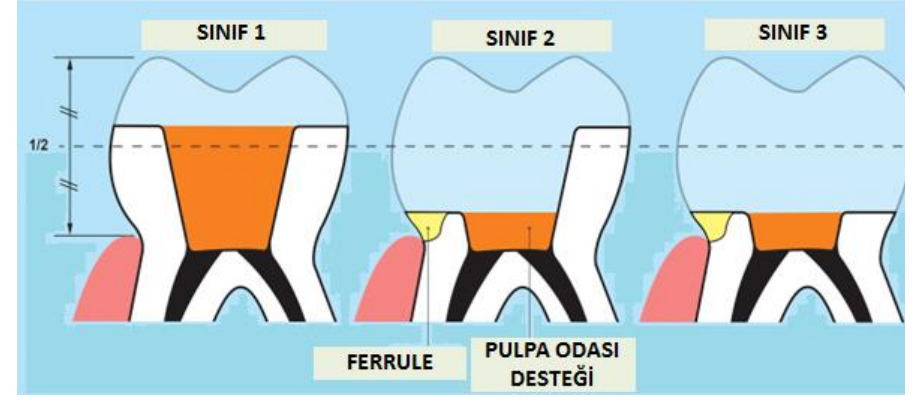

Şekil 1.

Endokron sinıflandırılmasının şematik görünümü ${ }^{21}$

\section{Endokron preparasyonu}

Endokron preparasyonuna başlamadan önce diş üzerinde mevcut olan eski dolgular kaldırımaktadır. Pulpa odasına girildiğinde siman ve guta-perka artıkları temizlenmektedir. Kavite derinliği her diş için farklılık göstermektedir. Bindl ve ark. $^{8}$ kronal desteğin sağlanması için kavite derinliğinin 2-4 $\mathrm{mm}$ arasında olması gerektiğini belirtmişlerdir. Pulpa odası anatomik forma uygun olarak hazırlanmaktadır. Pulpa odasında hazırlanan kavitede eğer düzensizlikler var ise rezin kompozit ile doldurulabilmektedir. Kavite duvarlarında 810 derece arası konus açısı hazırlanmaktadır. ${ }^{7}$ Kavite basamaklı hazırlanmakta ve uygun bir frez ile pürüzsüzleştirilmektedir. Endokronların oklüzal kalnlığı 3$7 \mathrm{~mm}$ arasında değişmektedir. Mörmann ve ark. ${ }^{22}$ endokronların oklüzal kalınlığının geleneksel kronlara göre yaklaşık 2 kat fazla olduğunun bu durumunda endokronların kırılma dayanımlarının daha yüksek olmasına imkân sağladığını belirtmişlerdir. Preperasyonu tamamlanan endokron restorasyonların ölçüsü konvansiyonel veya dijital ölçü yöntemleri ile alınabilir.

Endokron restorasyonlar ile yapılımış klinik çalışmalar

Endokron restorasyonların uygulandığı vaka raporlarının $7,23,24$ sunulduğu ve klinik takiplerin yapıldığı ${ }^{10,21}$ az sayıda çalışma bulunmaktadır.

Bindl ve Mörmann ${ }^{10} 208$ endokronun klinik başarısını araştırdıkları çalışmalarında, premolar dişlere uygulanan endokron restorasyonların başarısının molar dişlere uygulanan restorasyonlardan daha düşük olduğunu belirtmişlerdir. Bu durumun; premolar dişlerin yüzey alanlarının daha az olması ve kron boylarının daha uzun olması nedeniyle olabileceğini belirtmişlerdir.

Biacchi ve ark. $^{7}$ molar dişe uyguladıkları tam seramik endokron restorasyonları 3 yıl takip etmişlerdir. Üç yılın sonunda restorasyonların uyumunun iyi olduğunu, periodonsiyumun sağlam olduğunu, distal yüzde diş dokusunda meydana gelen kaybın ise kanal morfolojisi ve periodontal problemlerden kaynaklandığını belirtmişlerdir. 
Belleflamme ve ark. ${ }^{21}$ endokron restorasyonların klinik başarılarını inceledikleri çalışmalarında endokron restorasyonları 10 yıla kadar takip etmişlerdir. Araştırmacılar aşırı kron harabiyeti olan dişlerde ve parafonksiyonel alışkanlıkları bulunan bireylerde endokron restorasyonların başarı şansının yüksek olduğunu belirtmişlerdir. Klinisyenlerin endokron restorasyonları geleneksel fiber-post restorasyonlara alternatif olarak değerlendirmeleri gerektiğini bildirmişlerdir.

Bilgin ve ark. ${ }^{24}$ süt dişlerine pulpotomi tedavisi sonrası uyguladıkları endokron restorasyonu 9 ay boyunca takip etmişlerdir. Araştırmacılar endokron yapılan dişin radyografisini incelediklerinde pulpal veya periradiküler dokularda herhangi bir problemin mevcut olmadığını ve restorasyonun marjinal uyumunun çok iyi olduğunu belirtmişlerdir.

\section{Endokron restorasyonlar ile yapılmış laboratuar çalışmaları}

Zarone ve ark. ${ }^{12}$ yaptıkları çalışmalarında santral dişler ile 7 grup oluşturmuşlar ve sonlu elemanlar analizi yöntemi ile stres dağılımlarını incelemişlerdir. Kontrol grubu olarak hiçbir işlem görmemiş santral dişleri incelemişlerdir. Araştırmacılar endokron restorasyonların geleneksel postkron sistemlerine göre daha az stres oluşturduğunu belirtmişlerdir. Ayrıca hem post-kron sistemlerinde hem de endokron restorasyonlarında alümina gibi daha sert malzemelerin stres değerlerini arttırdığı; bu nedenle sert malzemeler yerine daha yumuşak olan kompozitin kullanılmasının klinik açıdan daha iyi olabileceğini belirtmişlerdir.

Lise ve ark. ${ }^{20}$ endokron ve fiber post üzerine kron restorasyonlarının kırıma dayanımlarını inceledikleri çalışmalarında; 6 alt grup oluşturmuşlardır. Gruplar 2,5 $\mathrm{mm}$ ve $5 \mathrm{~mm}$ derinliğinde endokron restorasyonlar ve 5 $\mathrm{mm}$ derinliğinde uygulanan fiber post üzerine kor yapımını takiben uygulanan kron restorasyonları kompozit ve tam seramik ile yapmışlardır. Araştırmacılar bütün grupların çiğneme kuvvetlerini karşılayacak kadar dayanıkı olduğunu belirtmişlerdir.

Guo ve ark..$^{25}$ sağlam diş, endokron ve post-kor üstü kron restorasyonlarının kıııma dayanımlarını inceledikleri çalışmalarında; sağlam dişin kırılma dayanımının restorasyonlara kıyasla istatiksel olarak daha yüksek olduğunu belirtmişlerdir. Fiber post-kor üstü kron ve endokron restorasyonlarının kırıma dayanımlarının birbirine benzer olduğunu belirtmişlerdir.

Ramirez ve ark. ${ }^{19} 5 \mathrm{~mm}$ derinliğinde ve $10 \mathrm{~mm}$ derinliğinde hazırlanmış post-kor üzeri kron restorasyonlar ile endokron restorasyonları karşılaştırdıkları çalışmalarında kompozit ve tam seramik materyallerini değerlendirmişlerdir. Araştırmacılar ön keser dişlerde kısa post ve endokron kullanımının klinik kullanım için yeterli dayanımına sahip olduğunu ve bu gruplarda meydana gelen kırıkların tamir edilebilir olduğunu belirtmişlerdir.
Aktaş ve ark. ${ }^{26}$ zirkonya endokron, alümina endokron ve hibrit seramiklerden üretilmiş endokronların kırıma dayanımlarını incelemişlerdir. Araştırmacılar tüm malzemelerin kırıma dayanımı açısından klinik kullanıma uygun olduğunu belirtmişlerdir. Ancak zirkonya ile üretilmiş endokronlarda meydana gelen kırıkların tamir edilemez kırıklar olduğunu, hibrit seramik ile üretilen endokron retorasyonlardaki kırıkların ise tamir edilebilir olduğunu belirtmişlerdir.

Gregor ve ark. ${ }^{27}$ endokron restorasyonlarda rezin simanların etkisini inceledikleri çalışmalarında; 7,5 $\mathrm{mm}$ kalınlığa sahip endokron restorasyonaların simantasyonunda dual polimerize ve ışıkla polimerize rezin simanında yeterli tutuculuğu sağladığını belirtmişlerdir.

\section{SONUÇLAR}

Kron harabiyetinin fazla olduğu dişlerin tedavisi adeziv diş hekimliğinin gelişmesi ile beraber geleneksel post-kor üzeri kron restorasyonlarının yanı sıra endokron restorasyonlar ile yapılabilmektedir. Endokron restorasyonlar, mikromekanik ve makromekanik tutuculuğun aynı anda elde edildiği monoblok bir yapıdan oluşmaktadır. Literatürde endokron restorasyonlar genellikle lityum disilikat cam seramikten üretilmesine rağmen; kompozit, feldspatik porselen, rezin nano seramik, alümina seramik ve zirkonyadan üretilen restorasyonların değerlendirildiği in vivo ve in vitro çalışmalar da mevcuttur. Endokron restorasyonların geçmişinin kısa olması nedeniyle uzun dönem klinik çalışmaların sayısı azdır. Bu nedenle klinik kullanımının artması için daha fazla çalışmaya intiyaç vardır. 


\section{KAYNAKLAR}

1. Zhu Z, Dong XY, He S, Pan X, Tang L. Effect of Post Placement on the Restoration of Endodontically Treated Teeth: A Systematic Review. Int $\mathbf{J}$ Prosthodont. 2015; 28: 475-83.

2. Ree M1, Schwartz RS. The endo-restorative interface: current concepts. Dent Clin North Am. 2010; 54: 345-74.

3. Assif D, Gorfil C. Biomechanical considerations in restoring endodontically treated teeth Journal of Prosthetic Dentistry 1984; 71; 565-67.

4. Ross IF. Fracture susceptibility of endodontically treated teeth. Journal of Endodontics 1980; 6: 5605.

5. Soares CJ, Santana F, Silva NR, Pereira JC, Pereira CA. Influence of the endodontic treatment on mechanical properties of root dentin Journal of Endodontics 2007; 33: 603-6.

6. Sedrez-Porto JA, Rosa WL, da Silva AF, Münchow EA, Pereira-Cenci T. Endocrown restorations: A systematic review and meta-analysis. J Dent. 2016; 52: 8-14.

7. Biacchi GR, Mello B, Basting RT. The endocrown: an alternative approach for restoring extensively damaged molars. J. Esthet. Restor Dent. 2013; 25: 383-90.

8. Bindl A, Mörmann WH. Clinical evaluation of adhesively placed Cerec endo-crowns after 2 years - preliminary results. J Adhes Dent. 1999; 1: 255-65.

9. Pissis $P$. Fabrication of a metal-free ceramic restoration utilizing the monobloc technique Practical Periodontics and Aesthetic Dentistry 1995; 7: 83-94.

10.Bindl A, Mörmann WH. Clinical evaluation of adhesively placed Cerec endocrowns after 2 years preliminary results Journal of Adhesive Dentistry 1999; 1: 255-65.

11. Chaio C, Kuo J, Lin Y, Chang Y Fracture resistance and failure modes of CEREC endo-crowns and conventional post and core-supported CEREC crowns Journal of Dental Sciences 2009: 4: 110-7.

12.Zarone F, Sorrentino R, Apicella D, Valentino B, Ferrari M, Aversa R, Apicella A. Evaluation of the biomechanical behavior of maxillary central incisors restored by means of endocrowns compared to a natural tooth: a 3D static linear finite elements analysis. Dent Mater. 2006; 22: 1035-44.

13. Bindl A, Richter B, Mörrmann WH Survival of ceramic-computer-aided/manufacturing crowns bonded to preparations with reduced macroretention geometry International Journal of Prosthodontics 2005; 18: 219-24.

14. Biacchi GR, Basting RT. Comparison of fracture strength of endocrowns and glass fiber postretained conventional crowns. Oper Dent 2012; 37: 130-6.
15.Dejak B, Młotkowski A. 3D-Finite element analysis of molars restored with endocrowns and posts during masticatory simulation. Dent Mater. 2013; 29: 309-17.

16. Biacchi GR, Basting RT. Comparison of fracture strength of endocrowns and glass fiber postretained conventional crowns. Oper Dent. 2012; 37: 130-6.

17.Dietschi D, Duc O, Krejci I, Sadan A. Biomechanical considerations for the restoration of endodontically treated teeth: a systematic review of the literature, Part II (Evaluation of fatigue behavior, interfaces, and in vivo studies). Quintessence Int 2008; 39: 117-29.

18. Rocca GT, Rizcalla N, Krejci I. Fiber-reinforced resin coating for endocrown preparations: a technical report. Oper Dent 2013; 38: 242-8.

19.Ramirez-Sebastia A, Bortolotto T, CattaniLorente M, Roig M, Krejci I. Adhesive restoration of anterior endodontically treated teeth: influence of post length on fracture strength. Clin Oral Investig 2014; 18: 545-54.

20.Pedrollo Lise D, Van Ende A, De Munck J, Umeda Suzuki TY, Cardoso Vieira LC, Van Meerbeek B. Biomechanical behavior of endodontically treated premolars using different preparation designs and CAD/CAM materials. J Dent. 2017; 59: 54-61.

21. Belleflamme MM, Geerts SO, Louwette MM, Grenade CF, Vanheusden AJ, Mainjot AK. No post-no core approach to restore severely damaged posterior teeth: An up to 10-year retrospective study of documented endocrown cases. J Dent. 2017; 63: 1-7.

22. Mörmann WH, Bindl $A$, Lüthy $H$, Rathke $A$. Effects of preparation and luting system on allceramic computer-generated crowns. Int $\mathrm{J}$ Prosthodont. 1998; 11: 333-9.

23. Fernandes da Cunha L, Gonzaga CC, Pissaia JF, Correr GM. Lithium silicate endocrown fabricated with a CAD-CAM system: A functional and esthetic protocol. J Prosthet Dent. 2017; 118: 131-4.

24.Bilgin MS, Erdem A, Tanriver M. CAD/CAM Endocrown Fabrication from a PolymerInfiltrated Ceramic Network Block for Primary Molar: A Case Report. J Clin Pediatr Dent. 2016; 40(4): 264-8

25.Guo J, Wang Z, Li X, Sun C, Gao E, Li H. A comparison of the fracture resistances of endodontically treated mandibular premolars restored with endocrowns and glass fiber postcore retained conventional crowns. J Adv Prosthodont. 2016; 8: 489-93 
26. Aktas G, Yerlikaya H, Akca K. Mechanical Failure of Endocrowns Manufactured with Different Ceramic Materials: An In VitroBiomechanical Study. 2016 Jul 28. doi: 10.1111/jopr.12499.

27.Gregor L, Bouillaguet S, Onisor I, Ardu S, Krejci I, Rocca GT. Microhardness of light- and dualpolymerizable luting resins polymerized through 7.5-mm-thick endocrowns. J Prosthet Dent. 2014; 112: $942-8$.

Yazışma Adresi:

Melahat ÇELIK GÜVEN

İstanbul Yeni Yüzyıl Üniversitesi

Diş Hekimliği Fakültesi Hastanesi

Sütlüce Mahallesi Binektaşı Sokak No:10

Beyoğlu, İstanbul, Türkiye

Tel : +902122557272

GSM : +90 5057706261

E-mail: melahatcelik_@hotmail.com 